\title{
Subjetividade e intersubjetividade entre semiótica e fenomenologia ${ }^{1}$
}

\author{
Francesco Marsciani
}

Resumo: Uma teoria semiótica da subjetividade não pode prescindir de uma consideração radical da dimensão intersubjetiva que representa, na perspectiva fenomenológica, a instância constitutiva do sentido do mundo. A teoria da significação ainda não conciliou-se suficientemente com esta opção fundamental: uma teoria da enunciação, por exemplo, se encontra até agora presa na alternativa entre uma percepção egológica da produção do sentido e uma concepção verdadeiramente intersubjetiva. Um entendimento radicalmente intersubjetivo da constituição de sentido deve integrar, na teoria da enunciação, uma autêntica teoria da alteridade, na qual se pode descrever a produção de intenções comunicativas a partir de uma intencionalidade transcendental mais fundamental.

Palavras-chave: subjetividade; intersubjetividade; enunciação; intencionalidade; sentido.

Abstract: Subjectivity and intersubjectivity between semiotics and phenomenology - A semiotic theory of subjectivity cannot prescind from a radical consideration of the intersubjective dimension, which, from the phenomenological perspective, represents the constitutive instance of the meaning of the world. The theory of signification has yet to come to terms with this fundamental option: the theory of enunciation, for example, is still tied to the alternative between an egological perception of the production of meaning and a truly intersubjective conception. A radically intersubjective understanding of the constitution of meaning must, in the theory of enunciation, include an authentic theory of alterity in which the production of communicative intentions can be described based on a more fundamental transcendental intentionality.

Keywords: subjectivity; intersubjectivity; enunciation; intentionality; meaning.

Em torno do tema da subjetividade, como bem se sabe, foram desenvolvidas muitas reflexões e consumadas muitas posturas, diversas explorações possíveis e tantas disputas, no curso de um considerável intervalo de tempo. Subjetividade de qual sujeito, um sujeito assujeitado ao predicado ou um sujeito enquanto fonte inesgotável de sensibilidade/

1 Esse texto foi originalmente publicado como Soggettività e intersoggettività tra semiotica e fenomenologia. In: Semiotica delle Soggettività. Per Omar. I saggi di Lexia n. 11. Roma: Aracne Editrice. 2013. 
significação/significância? Sujeito pleno ou sujeito posicional? Sujeito da consciência ou instância de uma produtividade de cuja natureza não participa? Sujeito individual ou individuado, ou ainda, sujeito entendido como papel, personagem, máscara? Sujeito do sociólogo ou do psicólogo?

Na trama de um tal encalço pela subjetividade, boa parte da filosofia e das ciências humanas do século XX adicionou de bom grado a complicação (socialista?) da necessária e necessitante dimensão intersubjetiva, na qual a subjetividade não pode não ser inscrita nem concebida: o sujeito é um "entre-sujeitos" ou, em outras versões, um "sujeito-semprecoletivo", pois não sabemos conceber - nos dias atuais, lembre-se - uma subjetividade que não se determine culturalmente, sobre um fundo de compartilhamento antropológico de condições de existência e de insistência. A cultura, qualquer coisa que ela seja, nos tornaria sujeitos intersubjetivamente determinados; antes, em primeiro lugar, intersujeitos, cujas formas de individuação deveriam poder variar segundo as linhas mais ou menos regulares de uma gênese real.

A fenomenologia, em sua completude, seguiu acuradamente o desenvolvimento de uma teoria filosófica da subjetividade, fazendo dela um dos caminhos principais sobre o qual proceder e, em seus êxitos, colocou em primeiro plano, com uma dramática surpresa, o tema - que parece constitutivo - da intersubjetividade transcendental.

Quinta meditação cartesiana de Husserl: depois de ter retraçado na autopercepção do Ego as estruturas da consciência que justificam (fundam?) a significação do mundo dos fenômenos, a fenomenologia se depara com a evidência de que, justamente lá, naquele mundo dos fenômenos-para-mim dos quais o Ego é o fundamento, em meio àqueles fenômenos-mundo, todos objetos de alguma forma de doação de sentido, existem algumas entidades que não se contentam em serem objetos-para-mim, fenômenos-paramim, mas parecem querer reproduzir, cada uma no seu próprio Ego autopercebido, a própria máquina da constituição do mundo, a própria necessária curvatura. Isto possui o surpreendente efeito de tornar-me, eu, que parecia agir como origem do sentido do fenômeno-mundo, constituído por minha vez como um fenômeno-objeto, entre os tantos dos quais se compõe o fenômeno mundo daquele outro Ego. Eu constituo o mundo, e nele vive um outro constituidor de mundo, muitos outros constituidores de mundo que parecem constituir, por sua vez, a minha própria consciência como fenômeno, entre os tantos fenômenos daquele mundo que é o deles. A coisa mais interessante desta situação paradoxal é que não temos o que fazer com mais mundos (não é uma questão de "mundos possíveis", fique bem claro), mas o jogo das constituições recíprocas vale sobretudo na medida em que o mundo seja o mesmo, um mesmo mundo que contém, qual horizonte de sentido, eu como sujeito e eu como objeto, e assim o outro como sujeito e o outro como objeto, em uma reciprocidade que não tem nada de alternância do "primeiro eu depois tu", mas sim da atribuição de posições, de papéis em jogo, de posições tornadas possíveis por uma revisão leibniziana (que está na carta de Husserl) de uma conceitualidade, 
e de uma terminologia, precedente e rigorosamente cartesianas. Na Quinta meditação cartesiana se passa de fato, como foi muitas vezes sublinhado, de uma constituição de sabor egológico a uma constituição de sabor monadológico, uma constituição que prevê e pressupõe um quadro constitutivo de ordem sistêmica, na qual o mundo se dá como horizonte de sentido propriamente intersubjetivo, tornado possível por uma intersubjetividade que não é aquela do "existe eu e existe também tu", do "eu e tu estamos juntos a compartilhar o mundo", mas aquela feita de uma recíproca dependência e determinação de posições de sentido, na qual "eu sou porque, no constituir-te, sou por ti constituído", na qual "eu sou na medida em que teu mundo me prevê e que tu me fazes ser o teu mundo, da mesma maneira como tu és parte do meu mundo". Nesta nova ótica, que é uma ótica propriamente sistêmica, e posicional a seu modo, estão em jogo pontos de vista que direcionam o olhar à alteridade e que a fazem ser fenômenomundo, enquanto não-incompossível com todas as determinações subjetivas de mundo. Na dimensão da constituição transcendental, assim concebida como sistema monadológico de compossíveis, não existem diversos mundos, dos quais cada um pertenceria solipsisticamente a cada um sujeito Ego, mas um só fenômeno-mundo, que é o mundo qual horizonte sistêmico, que articula as próprias condições subjetivas de possibilidades.

Com esta descoberta, por assim dizer, a fenomenologia atinge uma espécie de limite do próprio percurso, no fundo do qual a determinação última do sentido do fenômeno-mundo se revela como produzida em uma dimensão que é aquela própria de uma estrutura de sentido que se auto-organiza, que assume transcendentalmente as formas de uma significância na qual a subjetividade é modulada na reciprocidade, uma subjetividade intersubjetiva na qual cada um é outro porque é pelo outro e, assim, dão sentido a um mundo que é o mesmo, porque é o único no qual a determinação recíproca pode exercitar-se.

Esta fenomenologia, que corresponde, além disso, às formas que ela toma em outras obras, como a Crise das ciências europeias e, sobretudo, nas reflexões da segunda fase de Merleau-Ponty, é a mesma fenomenologia que pede a uma teoria do sentido como sistema que se auto-organiza - em outras palavras, uma semiótica - para prosseguir na estrada de uma autorreflexão que, por hora, parece dever ser entendida enquanto sentido que dá forma ao sentido, sentido do mundo que, como dizíamos, contém as instâncias da própria significação, isto é, a subjetividade frente à qual tem propriamente sentido. Deste ponto de vista, por uma semiótica que intencione responder ao chamado, por uma semiótica que queira fazer-se teoria da constituição do sentido, a forma intersubjetiva da instância constitutiva, que não é outra coisa que o sentido que produz individuações, é a própria forma das articulações, dos desdobramentos, da geração do significado.

Ora, para uma tal semiótica, o tema da intersubjetividade não pode mais ser tratado como o efeito de uma multiplicação de "subjetividades", de instâncias individuais que precisam ser reconhecidas como grupos de sujeitos, como coletivos, como "eu com tu", 
como sociedade. A intersubjetividade fenomenológica não é uma questão social, não é um modo refinado de dizer sociedade e cultura. A intersubjetividade fenomenológica é a própria condição para que se possa pensar a significação como desenvolvimento de estruturas sistêmicas, como sentido relacional, como lógica das determinações recíprocas. A intersubjetividade fenomenológica é mais da ordem das morfogêneses que das associações, muito mais da ordem das gestalten do que do associacionismo atomístico; são individuações entre campos relacionais e topológicos, lógicas dos sistemas, dinâmicas estruturais, e não turnos de fala, regras conversacionais, ou instituições da vida associada.

Segundo esta opção que é completamente epistemológica, na medida em que decide por uma postura "científica" nos confrontos do fenômeno sentido e de sua necessária propensão a ser entendido enquanto sensíveis, enquanto articuláveis na significação real dos efeitos que produzem, das formas de objetos que dão vida e dos sujeitos que nela resultam, segundo esta opção que é também filosófica, mas ao mesmo tempo metodológica, uma teoria da intersubjetividade transcendental é imediatamente uma teoria semiótica, ou uma teoria da articulação do sentido e uma teoria do valor:

1) o sentido se articula significando-se, e isto graças às diferenciações manifestadas por meio de cada articulação de substância;

2) a significação é atual, caso contrário, ela não existe; o que comporta uma instância pela qual, ou diante da qual, ela vale enquanto sentido articulado ou, caso se queira, nos confrontos dos quais o valor resulta enquanto valorável.

Semiótica, portanto. Semiótica é a razão que se abre sobre esta nova dimensão, semiótico é o olhar que aponta sobre a significação do fenômeno-mundo como polo objetivo de uma correlação essencial, aquela de natureza fenomenológica, entre sujeito-objeto, que não é outra coisa que a possibilidade mesma do fenômeno de valer, ou a possibilidade que o sentido possui de significar.

Mas em que modo o fenômeno-mundo é sentido por um sujeito que se dá, antes de tudo, como intersubjetividade? O que quer dizer ser sensível, para o mundo, e o que quer dizer ser intersubjetiva, em referência à instância que garante a significação atual deste mesmo mundo? Em que modo compreendemos o fato de que não é suficiente uma fundação egológica do valor do mundo, mas temos necessidade de um mundo enquanto correlacionado em uma intersubjetividade transcendental? O fato é que aquilo o que joga no mundo, seja enquanto objeto ou enquanto alter-ego, ou melhor, outra subjetividade, é a alteridade entendida, ou aquela da externalização do ser fora de si no sentido do mundo, no não poder se perceber como sujeito, senão pelo fato de que tencionamos um mundo e que este é um mundo que me constitui, a partir daquele ponto cego que é o outro. O mundo é a minha casa, onde o sentido é compreensão e valor, pois nesta casa habita o outro-em-mim que é, ao mesmo tempo, objeto da minha compreensão e sujeito que me concerne, que me entende, que me designa um posto, exatamente como eu designo 
um posto a ele, no sentido que ali habita. O outro que me atribui um olhar que, sendo meu, é por ele requerido, o outro que escuta a minha voz com as minhas próprias orelhas, o outro que me acaricia com a sua pele sobre a minha mão, que satisfaz minha sede com as suas ondas e me refresca com o hálito do vento, aquele outro é a única garantia do mundo que habito, a única convergência de intenções que me permite estabilizar a correlação sujeito-objeto, de deter a oscilação obscena do indeterminado, de acolher sob o meu fogo objetos-mundo que respondem com o seu significar à minha demanda, à minha urgência de valor. É precisamente uma semiótica da validade do valor que é convocada pelo convergir histórico de duas tradições, a fenomenológica e a estrutural, como resposta dos sistemas estruturais à descoberta da lateralidade monadológica do outro (resultado da fenomenologia madura), de um lado e, do outro e ao mesmo tempo, lugar para a determinação da instância de produção de sentido no interior do espaço vazio de subjetividade, espaço sem ego, inconsciente e plural, no qual as estruturas dissipam o fora de si.

Externalizar é dizer "eu" (HUSSERL, 1954, §54), em um tipo de versão husserliana da enunciação. Assim que o Eu diz "eu", abre-se novamente o espaço do paradoxo no qual eu sou aquilo que, de fora, aponta em direção a mim, me constitui como ele, que pode tomar o posto de um dêitico que provém do enunciado, que não é Eu, mas o seu produto. O famoso "Eu é um outro" pode ser lido segundo uma dúplice orientação, que nomearemos subjetivante e objetivante: sou Eu que me reconheço como outro em mim, me dissipo naquele que não sou, ou me encontro quando me tomo como o outro que diz "eu"? O Eu se descobre vazio de sentido, ou se descobre pleno do sentido daquilo que é outro?

Diante de mim, no mundo, habitam sujeitos e objetos, objetos que são sujeitos e para os quais eu sou sujeito e objeto. Do que depende a decisão, do que provém o ser sujeito ou objeto no mundo do sentido, de uma suposição qualquer, que se assume para se determinar? Quando eu e/ou o outro, e aquilo que somos, passamos a ser sujeitos de validade, "aquele para o qual", "aquele diante do qual" o mundo é um mundo de sentido? No circuito da alteridade que constitui intersubjetivamente cada sujeito, a decisão por uma instanciação de subjetividade pode provir somente do outro, de cada outro que coabita o mundo e com o qual, sob a regra do qual, com base no qual, o mundo se constitui como mundo de sentido.

Este mundo do sentido é um mundo enunciado, é a própria cena discursiva, aquela que em sua formação prevê - porque pressupõe e ao mesmo tempo determina a instância de sua validade. De que natureza é, portanto, esta instância de validade, esta subjetividade que é o polo correlativo do ser, objeto de sentido por parte do mundo? Uma reflexão sobre os procedimentos de enunciação, é evidente, beneficiou-se profundamente das pesquisas benvenistianas sobre a subjetividade da e na linguagem, pesquisas estas que fizeram história e escola. Não há quem não tenha passado um tempo entusiasmante na leitura e no aprofundamento das percepções de Benveniste sobre o mundo, em cuja 
linguagem se produzem efeitos de subjetividade a partir da articulação da categoria de pessoa, por meio da qual torna-se possível apreender o limiar entre o discurso enunciado e sua produção, como um lugar de dinâmica intensa na determinação dos postos que o discurso convoca e envolve.

Sobre a enunciação em Benveniste, no entanto, pode-se fazer duas leituras alternativas: uma, mais classicamente fenomenológica, é aquela que vê a posição de subjetividade como a instância que encontra nas formas linguísticas os instrumentos adequados para significar-se, para exprimir-se e comunicar-se; a outra é aquela que vê a posição de subjetividade como produtora tout court do evento-discurso, como seu simples pressuposto, como limiar da sua validade 2 .

O mais interessante ainda é que esta alternativa entre possíveis leituras retorna às passagens em que Benveniste tira suas próprias conclusões sobre a predominância, em sentido constitutivo, da relação de intersubjetividade em relação à instância de subjetividade simples. Ainda neste caso, existem algumas passagens nas quais pareceria que Benveniste faz a relação intersubjetiva (uma relação de comunicação) preceder a produção do sujeito linguístico; outras, nas quais é, ao contrário, o sujeito linguístico que, no ato de produção do discurso, se divide e se multiplica na posição do sujeito discursivo outro. Além disso, a questão da intersubjetividade do discurso não passa de um daqueles lugares nos quais se verifica, de maneira paradoxal e sempre dúplice, cada concepção da subjetividade, uma vez que se seja colhido, no seu sentido profundo, o percurso realizado pela tradição crítica frente às constituições do mundo, a partir de instâncias subjetivas doadoras de sentido.

Assim, a partir destas reflexões - que são aquelas de Benveniste, mas que também são consequências que muitos souberam, depois, conduzir em direções distintas ${ }^{3}$ - vale a pena tentar repensar os termos da relação enunciado/enunciação, em versão radicalmente intersubjetiva. A fim de evitar que a profundidade de uma visão fenomenológicaestrutural se disperse na banalidade de uma versão pragmática, por assim dizer, da relação com o outro na sua solução em termos comunicacionalistas, como se o outro fosse simplesmente aquele "outro-como-eu" ao qual me endereço na transmissão dos enunciados; a fim de evitar que a intersubjetividade se dilua nas passagens das sucessões conformistas e "democráticas", para as quais eu sou ele que atende o próprio turno antes de manifestar intenções; a fim de evitar que a troca intersubjetiva seja pensada como uma colocação em relação de sujeitos preconstituídos, e encontrar-se assim obrigado a fundar a natureza do sujeito enquanto tal em alguma metafísica irrefletida; para favorecer, enfim, uma descrição adequada dos mecanismos semióticos que presidem a constituição da validade do mundo-objeto e, ao mesmo tempo, do sujeito do valor,

2 Para um aprofundamento, me permito remeter ao meu Ricerche semiotiche I (Esculapio, Bolonha 2012), em particular ao capítulo 1.4.2.

3 Entre todos, gostaria de sublinhar os nomes de Foucault e de Greimas. Creio que estão, entre eles, os maiores méritos de uma perspectiva de semiótica discursiva. 
uma semiótica verdadeiramente intersubjetiva é requerida e como tal é construída, ao menos nos termos de um olhar, de uma tomada de posição, de um ponto de vista que dê conta do sentido de um percurso de pensamento e de uma série de condições teóricas relevantes. Uma semiótica tal poderia ser uma semiótica que pensa a significação do mundo, assim como desejava a fenomenologia, nos termos de um discurso enunciado, frente ao qual imaginar a instância subjetiva da validade como aquela para a qual tal enunciado tem sentido, um tipo de enunciatário do mundo, um destinatário das valorizações e das diferenciações que articulam em objetividade de sentido o próprio mundo. O sentido é dado, é sempre dado, e o fato de que, enquanto enunciado, pressupõe uma enunciação, não comporta necessariamente que tal enunciação seja entendida como a instância de sua produção real. Mais corretamente, porém, uma tal instância pressuposta é simplesmente, certamente e necessariamente, a instância de validação subjetiva do sentido objetivado; não é outra coisa que a pressuposição do sentido mesmo que, enquanto enunciado, o enunciado do discurso assume-se como indissoluvelmente relacionado com o seu futuro, o seu vir-ao-mundo: não seria enunciado se não fosse evento sensível, se não fosse sentido do mundo que, repentinamente, de volta em volta, se manifesta. Este sentido, que necessariamente possui, é aquele que requer um enunciatário, em relação ao qual ele seja aquele que é: nada mais que, justamente, sentido enunciado.

Tal concepção recusa-se, evidentemente, a considerar a estrutura formal da enunciação como fundada na posição do Eu enunciante, atribuindo ao enunciador um tipo de potencialidade geradora de enunciados-discurso. Não é o enunciador o assim dito "sujeito da enunciação" (como gostaria Coquet, por exemplo), não é a partir da sua posição, que não poderia ser outra além da posição de um sujeito fenomenológico primeiro, aquela do sujeito de consciência que se autopercebe nas estruturas originárias do Ego, aquele do corpo-próprio enquanto modelo individual e humano-demasiadamente humano de subjetividade incorporada, aquele de uma intencionalidade que muito frequentemente se confunde com as intenções. Este é um modelo de subjetividade enunciante, que tende a aceitar a subcategorização benvenistiana da categoria de pessoa em "pessoa subjetiva" vs. "pessoa não-subjetiva" (Eu vs. Tu) sem que se entenda com clareza sobre qual função ela possa repousar, se não aquela de uma responsabilidade predicativa, que não tem nenhuma das doações de sentido, mas todo um modelo sociopsicológico do uso comunicativo da linguagem.

Ao contrário, uma concepção da relação de pressuposição enunciado-enunciação, para ser formalmente construída na imanência de uma teoria das suas condições, pode bem postular uma dominância do Tu, uma preeminência ou prevalência do enunciatário sobre o enunciador, porque uma tal oposição não se funda sobre um modelo comunicativo alternativo, não troca um por outro os dois atores da comunicação real, mas coloca como tal o problema da significação do enunciado-mundo, de seu ser por vezes aquele que é por qualquer um, por uma subjetividade constitutivamente intersubjetiva, vale dizer 
por uma subjetividade que é subitamente fonte de alteridade, razão de alteridade, alteridade autêntica: alteridade radical, lembre-se, em relação àquele mundo no qual, enquanto enunciados, os sujeitos podem trocar-se entre si como objetos, como "eu que te sou próximo", como "agora eu depois tu"; trata-se, no caso deles, de sujeitos constituídos no enunciado, de papéis segundo a forma de cada um, e não, como é o caso da instância intersubjetiva, da condição mesma do sentido enunciado que produz objetividade.

Diante do mundo, no fenômeno-mundo, é colocado, porque pressuposto, um enunciatário que tem em si a natureza da intersubjetividade transcendental. É, provavelmente, o que bem tinha observado o próprio Greimas que escrevia, no Dictionnaire, primeiramente no verbete "Énonciateur/énonciataire":

Assim compreendido, o enunciatário não é apenas o destinatário da comunicação, mas também o sujeito produtor do discurso, a "leitura" sendo um ato de linguagem (um ato de significação) ao longo da produção do discurso propriamente dito. O termo de "sujeito da enunciação", empregado frequentemente como sinônimo de enunciador, recobre de fato as duas posições actanciais de enunciador e de enunciatário. ${ }^{4}$ (GREIMAS \& COURTÉS, 1979)

E no verbete "Énonciation", depois:

O mecanismo da enunciação [...] corre o risco de permanecer sem fundamento se nele não for inscrito o essencial, aquilo que o alavanca, o que faz com que a enunciação seja um ato entre outros, a saber, a intencionalidade. Recusando o conceito de intenção (por meio do qual alguns tentam fundar o ato de comunicação, este repousando sobre uma 'intenção de comunicar') - mesmo se apenas porque ele reduz a significação à única dimensão consciente [...] preferimos aquele da intencionalidade que interpretamos como uma 'visão do mundo', como uma relação orientada, transitiva, graças à qual o sujeito constrói o mundo enquanto objeto, construindo-se assim ele mesmo. ${ }^{5}$ (GREIMAS \& COURTÉS, 1979)

O que parece construir-se nesta concepção da relação entre enunciado e enunciação é a ideia de que, diante de um mundo que é enunciado-discurso - e enquanto tal, função

4 Nota da tradutora. No original: "Ainsi compris, l'énonciataire n'est pas seulement le destinataire de la communication, mais aussi le sujet producteur du discours, la 'lecture' étant un acte de langage (un acte de signifier) au même titre que la production du discours proprement dite. Le terme de 'sujet de l'énonciation', employé souvent comme synonyme d'énonciateur, recouvre en fait les deux positions actantielles d'énonciateur et d'énonciataire."

5 Nota da tradutora. No original: "Le mécanisme de l'énonciation [...] risque de rester sans ressort si l'on n'y inscrit l'essentiel, ce qui le met en branle, ce qui fait que l'énonciation est un acte parmi d'autres, à savoir l'intentionnalité. En refusant le concept d'intention (par lequel certains essaient de fonder l'acte de communication, celui-ci reposant sur une 'intention de communiquer') - ne serait-ce que parce qu'il réduit la signification à la seule dimension consciente [...] - nous lui préférons celui d'intentionnalité que nous interprétons comme une 'visée du monde', comme une relation orientée, transitive, grâce à laquelle le sujet construit le monde en tant qu'objet tout en se construisant ainsi lui-même." 
de uma atribuição de sentido que corresponde à intencionalidade fenomenológica transcendental, a mesma que funda a estrutura da intersubjetividade -, o assim dito sujeito da enunciação não pode ser outro além da própria intencionalidade, vale dizer, uma geral e abstrata função de significação enunciada e enquanto tal, cultivada, acolhida, vivida no vivo de uma constante formação e transformação do sentido. Diante do mundo enunciado, é colocado um enunciatário que constitui a dimensão intencional da qual depende o sentido do enunciado-discurso, como sustentou a fenomenologia até a sua versão mais radical, que é aquela da intersubjetividade transcendental; ao lado do enunciatário, todavia, se coloca o outro aspecto da instância da enunciação, seu segundo lado, o outro em que a alteridade se torna quando enunciada, a saber, o enunciador. Segundo esta hipótese, o enunciador, em vez de colocar-se como a origem e o motor da produção do enunciado, é o produto de uma atribuição que tudo deve à natureza intersubjetiva do enunciatário. É a alteridade radical que o habita, a externalização que o faz ser o valor do sentido enunciado, a impor ao enunciatário, em certo sentido, ou a conduzi-lo, caso se queira, na iniciativa de construir enunciadores, ou os correspondentes aos quais designar intenções, mais que intencionalidades, isto é, intenções de comunicar, um tipo de responsabilidade em relação ao enunciado-mundo que aparece, em vez de puramente dado, como produto de uma troca intencionada, mais ou menos consciente, mais ou menos voluntária, mas à qual poderia ser atribuído um tipo de razão de ser, de finalidade, de motivação. É assim que, diante do sentido dado o qual é sempre dado como um todo, como um mundo-por-inteiro - ocupam-se de repartir as posições de uma estrutura narrativizada da orientação motivante, das transformações finalizadas, de um sentido transmitido, de uma comunicação enquanto transformação incremental de valorizações.

Assim, a intersubjetividade produz sujeitos, que são as articulações nas quais, segundo uma estrutura de agregações singulares, se manifesta o sistema das dispersões subjetivas: os sujeitos que no fim, para a semiótica, são pensados como os responsáveis pelas transformações sensíveis, com suas competências e destinações, encontram-se a revestir os papéis simulacrais de um sentido do sentido, ao qual a instância intersubjetiva os chama, a fim de poder encontrar, no fora de si, no outro que realiza a alteridade da constituição, em cada enunciador que o enunciatário pode atribuir a intenção enunciativa, uma forma significável da produção do sentido.

Tradução de Marília Jardim e revisão de Mariana Ferraz de Albuquerque.

Francesco Marsciani é semioticista graduado em Filosofia, doutorado em Semiótica pela Università di Bologna, onde atua como pesquisador e professor de Semiótica junto 
ao DAMS de Bologna. Participou desde 1985 do grupo de pesquisa de Greimas em Paris, junto à EHESS. Sua pesquisa esteve voltada para as relações entre semiótica e fenomenologia, com análise de vários tipos de objetos, e etnossemiótica das práticas cotidianas. Entre suas publicações de livros destacam-se: em co-autoria com Alessandro Zinna: Elementi di Semiotica Generativa. Processi e sistemi della significazione, Esculapio, 1991 (introduzione di Algirdas J. Greimas); como organizador de coletânea: Miti e figure, Algirdas J. Greimas, curatore edizione italiana Esculapio, 1995 e como autor único: Esercizi di Semiotica Generativa. Dalle parole alle cose, Esculapio, 1999; Tracciati di Etnosemiotica, Franco Angeli, Milano, 2007; Ricerche semiotiche I. II tema trascendentale, Esculapio, 2012; Ricerche semiotiche II. In fondo al semiotico, Esculapio, 2012; Minima semiotica. Percorsi nella significazione, Francesco Marsciani, Mimesis Edizioni, 2012.

\section{Referências}

GREIMAS, A.J.; COURTÉS, J. Semiotique. Dictionnaire raisonné de la théorie du langage. Paris: Hachette, 1979.

HUSSERL, E. Die Krisis der europäischen Wissenschaften und die transzendentale Phänomenologie, in Philosophie, I, in: Husserliana: Edmund Husserl, gesammelte Werke, Band VI. Haag: Martinus Nijhoff, 1954. 